\title{
Protective Effect of Lepedium sativum against 2, 4-Dichlorophenoxyacetic Acid Hepatotoxicity: An Electron Microscopic Study
}

\author{
Tahani H. Dakhakhni1 ${ }^{*}$, Gehan A. Raouf ${ }^{2}$, Awatef Ali ${ }^{3}$ \\ ${ }^{1}$ Medical Biophysics Lab., King Fahd Medical Research Centre, King Abdulaziz University, Jeddah, KSA \\ ${ }^{2}$ Department of Spectroscopy, National Research Centre, Dokki, Egypt \\ ${ }^{3}$ Zoology Department, Faculty of Science, Alexandria University, Alexandria, Egypt \\ Email: ^dakhakhni0@gmail.com
}

How to cite this paper: Dakhakhni, T.H., Raouf, G.A. and Ali, A. (2020) Protective Effect of Lepedium sativum against 2, 4-Dichlorophenoxyacetic Acid Hepatotoxicity: An Electron Microscopic Study. Open Journal of Applied Sciences, 10, 825833.

https://doi.org/10.4236/ojapps.2020.1012058

Received: November 17, 2020

Accepted: December 20, 2020

Published: December 23, 2020

Copyright $\odot 2020$ by author(s) and Scientific Research Publishing Inc. This work is licensed under the Creative Commons Attribution International License (CC BY 4.0).

http://creativecommons.org/licenses/by/4.0/

\section{(c) (i) Open Access}

\begin{abstract}
Medicinal plants have been used to treat many diseases with fewer side effects compared to clinical medicines. The need for treatment by medicinal plants has been increasing in response to the accumulation of environmental pollutants. The herbicide 2, 4-Dichlorophenoxyacetic acid has been considered as fast spreadable environmental pollutant, which may cause many disorders in animals and possibly in humans. The aim of this study is to assess the protective and/or curative effect of Lepidium sativum against hepatotoxicity induced by 2, 4-D herbicide in rats. 25 Albino Wistar rats were grouped into 4 groups: a control group, the curative group treated for 4 weeks with LS water extract after a single dose $2,4-\mathrm{D} \mathrm{LD}_{50}$ administration, protective group which was treated for 4 weeks with LS water extract prior to the 2, 4-D LD $\mathrm{L}_{50}$ administration, and LS only group that was given the LS water extract as a positive control. Using transmission electron microscope, the histological features showed that curative group hepatocytes still suffered from focal necrosis and vacuolation of hepatocytes as a result of 2, 4-D toxic effect whereas in the protective group hepatocytes were less accentuated expressed as less frequent necrotic area, and still large mitochondria were present with numerous undissolved lipid droplets and a small amount of rough endoplasmic reticulum. For the LS only group, nearly normal cells with centric nucleus, normal small mitochondria were at a normal nucleus-cytoplasmic ratio, but a few lipid droplets were noticed. This study proved that curative group has an advantage over the protective group that could be presented in the nucleus with narrow nuclear pores and intact nuclear envelope with dense small mitochondria and normal rough endoplasmic reticulum that were recorded as in the control group. Thus, Lepidium sativum administration to the rats prior or post to intoxication was effective in minimizing the 2, 4-D-induced damages
\end{abstract}


likely through a free radical scavenging activity in liver tissue.

\section{Keywords}

Hepatoprotective, Toxicity, Lepedium sativum, 2, 4-Dichlorophenoxyacetic Acid

\section{Introduction}

Since the earliest civilizations, medicinal plants have been used to treat many diseases. Nowadays, there is an increased demand by patients to use herbal medicines with fewer side effects. The curative and the protective effect have been the point of interest of many studies. Recent studies such as [1] focused on the Echinacea purpurea that is a medicinal plant used against a variety of treatments, such as wound infections, snake bites in addition to its antioxidant, antitumor and anti-inflammatory properties. Moreover, [2] proved that Micromeria fruticosa Induces Cell Cycle Arrest and Apoptosis in Breast and Colorectal Cancer Cells. Lepidium sativum (LS), known as "Hab al Rashad", is one of the medicinal plants that grow in Saudi Arabia in several areas, such as the Eastern Province and Al-Qassim [3]. It is traditionally used in Saudi folk medicine treating many health conditions, but mainly healing bone infractures and improving health after maternity [4]. Moreover, LS is used to treat migraine [5], asthma, cough and bleeding [6]. In addition, it was proven to possess a hypoglycemic [7], antihypertensive, bronchodilatory effect, as well as its healing properties [7] [8] [9] [10]. The protective and/or curative effect against various toxicities, have been the focus of many studies. For example, [11] studied the protective effect of LS against 2, 4-D herbicide which is due to LS rich antioxidant content. It has been proven that LS also contains volatile essential aromatic oils, fatty oils, proteins, carbohydrates, fatty acids, vitamins, glycosides, flavonoids, essential oil, imidazole alkaloids and glucosinolates [12] [13]. Furthermore, [14] studied the Osteoprotective Activity and Metabolite Fingerprint via UPLC/MS and GC/MS of Lepidium sativum in Ovariectomized Rats. Their results revealed that $L$. sativum extract exhibited significant anti-osteoporotic actions due to LS content of glucosinolates, lignans, coumarins, phenolic acids, and alkaloids. Another study is from [15] which proved that Lepidium sativum seed extract is a beneficial protective supplementary agent against adverse effects of diabetes on male reproductive system.

Herbicides have been considered as fast spreadable environmental pollutants, which may cause many disorders in animals and possibly in humans. The herbicide 2, 4-Dichlorophenoxyacetic acid (2,4-D) is one the most commonly used synthetic herbicides throughout the world that was introduced in the market in the early 1940s [16]. 2, 4-D is a selective, systemic herbicide, used to control annual and perennial broadleaf weeds [17] with efficacy, broad spectrum control, and low price all of which made it the most used herbicide world widely. Agri- 
cultural fields, golf courses, lawns, and parks are the sites where 2, 4-D is applied, so humans are exposed to inhalation toxicity or via dermal contact. Vegetables and drinking water as well as soil contaminated with 2, 4-D also considered as main routes toxicity [16]. Various toxicities have been proved be associated with 2, 4-D exposure. For example, Thiel et al. [17] proved that exposure to the herbicide 2, 4-dichlorophenoxyacetic acid impairs mitochondrial function, oxidative status, and behavior in adult zebrafish. Hepatotoxicity induced by 2, 4-D had been the focus of many studies [18] [19] [20] [21]. Moreover, oxidative stress in brain was proved to be induced by the sub-acute administration of 2 , 4-D [16]. The relationship of 2, 4-D in testicular toxicity has been widely reported. However, the risk of early spontaneous abortion was reported to be increased by 2, 4-D exposure. In addition, many studies focused on testicular toxicity induced by 2, 4-D because incidence of asthenospermia, necrospermia, and teratospermia were noticed to be high in farmers dealing with 2, 4-D [22] [23]. In rodents, the exposure to 2, 4-D has been associated with many complications including loss of weight of the brain, reduction of AChE activity and testicular dysfunction [24].

Thus studying the antitoxic effect of LS against all these 2, 4-D induced toxic effects can be an important point to focus on. As the liver is the largest vital organ responsible for detoxification, the current study aims to investigate the hepatoprotective as well as the curative effect of LS water extract illustrated as the recovery in the cellular ultrastructural changes induced by $2,4-\mathrm{D}$ hepatotoxicity, monitored by the mean of electron microscopy.

\section{Materials and Methods}

\subsection{Chemicals and Preparation of Lepedium sativum Aqueous Extract}

The herbicide 2, 4-dichlorophenoxyacetic acid was purchased with the brand name $\left(2,4\right.$-Kill) from a local market, Jeddah, KSA. The $\mathrm{LD}_{50}$ dose of $639 \mathrm{mg} / \mathrm{kg}$ body weight according to [25] was prepared by taking $0.28 \mathrm{ml}$ of the liquid 2, 4-D and adding tap water to reach $0.5 \mathrm{ml}$.

Lepedium sativum seeds were purchased from a local market in Jeddah, Saudi Arabia and the aqueous extract was prepared according to the Moroccan traditional phytotherapy (decoction) [7]. One gram of powdered seeds was mixed with $100 \mathrm{ml}$ distilled water then boiled for $10 \mathrm{~min}$. Thereafter, the aqueous extract was left to cool for 15 min then filtered using a Whatman filter paper (7.0 $\mathrm{cm})$ to remove particulate matter [7]. The filtrate was then freeze-dried and the desired dose was then reconstituted in $1.5 \mathrm{ml}$ of distilled water. The aqueous extracts were reconstituted daily, just before administration. The extracts obtained were then given orally to the groups of rats at a dose of $20 \mathrm{mg} / \mathrm{kg}$ body weight.

\subsection{Animals and Studied Groups}

The experimental work of the present study was prepared in the Medical Biophysics Laboratory at King Fahd Medical Research Centre, King Abdulaziz Uni- 
versity, Jeddah, Kingdom of Saudi Arabia.

In this study, a total number of 25 male albino Wister rats were supplied by King Fahd Medical Research Centre, with a mean initial body weight of 250 $350 \mathrm{~g}$. The animals were grouped randomly and were housed in plastic cages (70\% relative humidity, $24^{\circ} \mathrm{C} \pm 1^{\circ} \mathrm{C}$, and $12 \mathrm{~h}$ duration light and dark cycle).

Four groups of rats, with a minimum of four per group, were subjected to the following treatments:

1) Curative group: 4 rats were treated with $20 \mathrm{mg} / \mathrm{kg}$ LS water extract via oral gavage 24 hours after the administration of the single LD50 dose of 2, 4-D for 4 weeks.

2) Protective group: 4 rats were treated with LS water extract daily for 4 weeks, and for protective effect monitoring, these animals were given the 2, 4-D LD50 dose on the 28th day and then sacrificed.

3) LS only group: a positive control group with LS water extract administrated daily to 4 rats for 4 weeks to find out the effect of the aqueous extract of LS on liver and brain tissues, if any.

4) Control group: 4 rats that received daily equivalent volumes to $2,4-\mathrm{D}$ of water via oral gavage for 4 weeks.

\subsection{Tissue Collection}

Animals were sacrificed by decapitation and livers were rapidly removed and washed with saline. For fixation until analysis by transmission electron microscope (TEM), glutaraldehyde was added to the tissue.

\subsection{Tissue Preparation and Transmission Electron Microscopy}

The dissected livers were cut into cubes, fixed with glutaraldehyde in $0.2 \mathrm{M}$ Phosphate buffer for $5-6 \mathrm{~h}$ at $48^{\circ} \mathrm{C}$, then post fixed in $2 \% \mathrm{OsO}_{4}$ for $2 \mathrm{~h}$ at $48^{\circ} \mathrm{C}$. The pieces were dehydrated in an ethanol series, embedded in EPON/812 taab and then cut into $0.5 \mathrm{~mm}$ thick sections using an ultra-microtome (LKB, Sweden) and mounted on Nickel grids $(300 \mathrm{~mm})$. The sections were double stained with uranyl acetate and lead citrate to be examined by transmission electron microscope (Philips CM100, Netherlands) and photographed.

\section{Results}

The histological features shown by TEM have elucidated the effects of the LS anti-oxidative treatment against the herbicide toxicity. In the curative group, hepatocytes still suffered from focal necrosis and vacuolation of hepatocytes as a result of 2, 4-D toxic effect (Figure 1a) and (Figure 1b). The alterations in rat liver were less accentuated in the protective group. The necrotic area was especially less frequent, still large mitochondria were present with numerous undissolved lipid droplets (Figure 1c) and a small amount of rough endoplasmic reticulum (Figure 1d). In the LS only group, nearly normal cells with centric nucleus, normal small mitochondria at a normal nucleus-cytoplasmic ratio, but a 


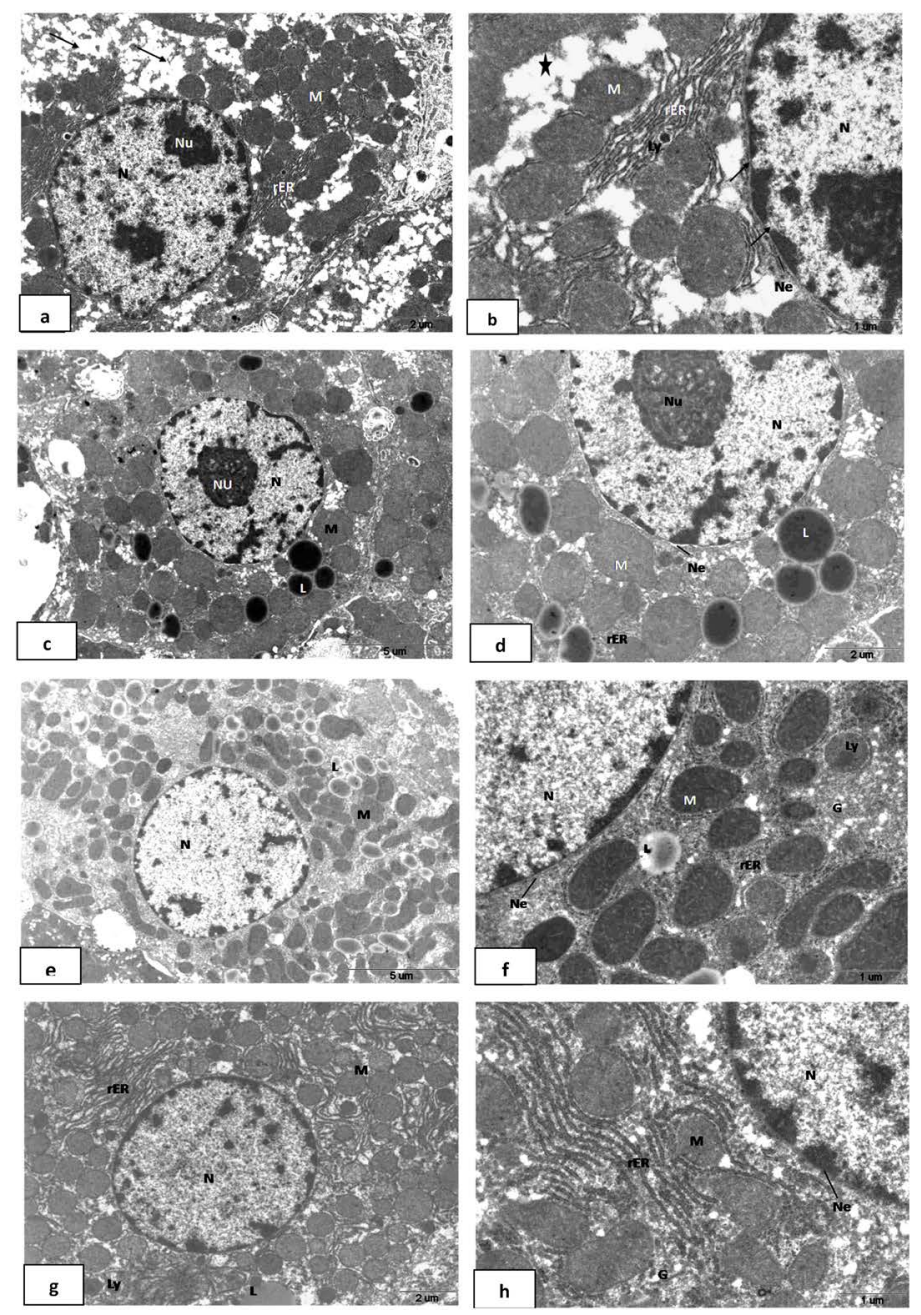

Figure 1. (a) The rat liver of curative group showing: nucleus $(\mathrm{N})$ with irregular nuclear envelope and two nucleolus $(\mathrm{Nu})$. Note, numerous small mitochondria $(\mathrm{M})$ in the lytic cytoplasm (arrows) (x4600). (b) Enlarged part from the previous figure showing: The nucleus $(\mathrm{N})$ with narrow nuclear pores (arrows) and intact nuclear envelope $(\mathrm{Ne})$, dense small mitochondria $(\mathrm{M})$ and normal rough endoplasmic reticulum (rER) lysosome (Ly) and focal necrosis (star) (x13,500). (c) The rat liver of protective group showing: hepatocyte with central euchromatic nucleus $(\mathrm{N})$ has large nucleolus $(\mathrm{Nu})$ and numerous large mitochondrial (M) and undisolved lipid droplets $(\mathrm{L})(\mathrm{x} 4600)$. (d) Enlarged part from previous fig showing: nucleus $(\mathrm{N})$ with low marignated heterochromatin, nucleolus $(\mathrm{Nu})$ and slightly dilated nuclear membrane $(\mathrm{Ne})$. Note, mitochondrial $(\mathrm{M})$, few rough endoplasmic reticulum (rER) and lipid droplet (x7900). (e) The rat liver of LS only group showing: nearly normal cell with centric nucleus $(\mathrm{N})$, normal small mitochondrial $(\mathrm{M})$ in normal nucleus - cytoplasmic ratio but with a few lipid droplets (L). (f) Enlarged part from fig (4.24) showing: Pale nucleus (N) with nuclear pores and contact nuclear membrane $(\mathrm{Ne})$. Note, mitochondrial $(\mathrm{M})$ rough endoplasmic reticulum (rER), secondary lysosome (Ly) and glycogen (G) (x4600). (g) The rat liver of water control group showing: Nearly normal cell with smooth regular central nucleus $(\mathrm{N})$ have small amount of marginal heterochromatin, numerous round or oval shaped mitochondria $(\mathrm{M})$, rough endoplasmic reticulum (rER), lipid droplet (L) and lysosomes (Ly) (x5800). (h) Enlarged part of the previous figure showing: Nucleus $(\mathrm{N})$ surrounded by double nuclear envelope $(\mathrm{Ne})$, mitochondria $(\mathrm{M})$ in contact with long rough endoplasmic reticulum (rER ) and glycogen (G) (x13,500). (Lead citrate \& uranayl acetate). 
few lipid droplets were noticed (Figure 1e). Also, there were pale nuclei with contact nuclear membrane, secondary lysosome and an accumulation of glycogen near lipid droplets (Figure 1f). In the control group, the hepatocyte architecture appears as was recorded before in the 4 weeks younger control group from our previous work [11], except for the presence of only a few lipid droplets (Figure 1g), in addition to the cytoplasm contained a nucleus surrounded by a double nuclear envelope and mitochondria in contact with long rough endoplasmic reticulum (Figure $1 \mathrm{~h}$ ).

\section{Discussion}

At the present time, the world is facing an increase in exposure to free radicals due to many pathological, lifestyle, and environmental situations. Consequently, the adequate antioxidants intake from food and/or supplements has been an essential requirement [26] to cope with such additional exposure to free radicals as the endogenous antioxidants defence may not be enough to eliminate this oxidative stress [27]. The herbicide 2, 4-D administration enhances the hepatic level of CYP2E1 gene (a member of the cytochrome P450 mixed-function oxidase system), which represents a significant source of reactive oxygen species and hence is known to play a role in some liver diseases [28]. Thus the recovery shown in the current study could be correlated to the presence of antioxidants in the LS seeds water extract and the good percentage of antioxidant activity as mentioned earlier, that can overcome the CYP2E1-induced oxidative stress in rat liver microsomes.

In this study, the anti-oxidative effect of LS aqueous extract was shown by the morphological findings in the hepatic tissue found in all LS treated groups. The LS water extract proved to have a curative/protective effect against 2, 4-D intoxication, with some advantages of the curative over the protective group. Although alterations in rat liver were less accentuated in the protective group and the necrotic area was especially less frequent, the protective group still has large mitochondria with numerous undisolved lipid droplets. The curative group has an advantage over the protective group that could be presented in the nucleus with narrow nuclear pores and intact nuclear envelope with dense small mitochondria and normal rough endoplasmic reticulum that were recorded as in the control group, even though the curative group hepatocytes still suffered from focal necrosis and vacuolation of hepatocytes. Both the LS only treated group and cont. hypatocytes micrographs exhibited nigligable changes and were comparable to each other although their IR spectral signature and intensity ratios showed significant and markable changes as proved in our previous study [11].

\section{Conclusion and Recommendations}

Lepidium sativum administration to the rats prior or post to intoxication was effective in minimizing the 2, 4-D-induced damages likely through a free radical scavenging activity in liver tissue. All the LS treated groups showed remarkable 
recovery from the adverse 2, 4-D intoxication. The LS water extract is postulated to have a significant antitoxic/antioxidant role against 2, 4-D induced hepatotoxicity, including its apoptotic effect. The inhibitory effects of the LS water extract against toxic damage are attributed to its antioxidant properties that provide protection by several mechanisms since it has $\mathrm{DPPH}, \mathrm{H}_{2} \mathrm{O}_{2}, \mathrm{O}_{2}^{-}$scavenging activities and chelating activity. It is recommended that more studies should be made on antitoxic/antioxidant effect of LS against various toxicities.

\section{Acknowledgements}

Deep thanks go to Mr. Abdullah Salawati, Mr. Zaki Al-Asouli, Mrs. Nourah Al-Otaibi, Mrs. Rasha Ahmed, Mrs. Rula Habbal, Mr. Mohammad Refai Ms. Dalal Albaroudi, and Mrs. Amal AlMustadi. This research work was supported by King Abdulaziz City for Science and Technology, Grant No. AT-125-18.

\section{Conflicts of Interest}

The authors declare no conflicts of interest regarding the publication of this paper.

\section{References}

[1] Coelho, J., Barros, L., Dias, M., Finimundy, T., Amaral, J., Alves, M., Calhelha, R., Santos, P. and Ferreira, I. (2020) Echinacea purpurea (L.) Moench: Chemical Characterization and Bioactivity of Its Extracts and Fractions. Pharmaceuticals, 13, 125-141. https://doi.org/10.3390/ph13060125

[2] El-Huneidi, W., Shehab, N.G., Bajbouj, K., Vinod, A., El-Serafi, A., Shafarin, J., Bou Malhab, L.J., Abdel-Rahman, W.M. and Abu-Gharbieh, E. (2020) Micromeria fruticosa Induces Cell Cycle Arrest and Apoptosis in Breast and Colorectal Cancer Cells. Pharmaceuticals, 13, 115-126. https://doi.org/10.3390/ph13060115

[3] Rahman, M.A., Mossa, J.S., Al-Said, M.S. and Al-Yahya, M.A. (2004) Medicinal Plant Diversity in the Flora of Saudi Arabia 1: A Report on Seven Plant Families. Fitoterapia, 75, 149-161. https://doi.org/10.1016/j.fitote.2003.12.012

[4] Golkar, F.H. and Koohi Dehkordi, M. (2018) Production of a New Mucilage Compound in Lepidium sativum Callus by Optimizing in Vitro Growth Conditions. Natural Product Research, 33, 130-135. https://doi.org/10.1080/14786419.2018.1437426

[5] Merzouki, A., Ed-derfoufi, F. and Mesa, J.M. (2000) Contribution to the Knowledge of Rifian Traditional Medicine. II: Folk Medicine in Ksar Lakbir District (NW Morocco). Fitoterapia, 71, 278-307. https://doi.org/10.1016/S0367-326X(00)00139-8

[6] Nadkarini, A.K. (1954) Indian Material Medica. Popular Prakashan Pvt. Ltd., Bombay, 736-737.

[7] Eddouks, M., Maghrani, M., Zeggwagh, N.A. and Michel, J.B. (2005) Study of the Hypoglycemic Activity of Lepidium sativum L. Aqueous Extract in Normal and Diabetic Rats. Journal of Ethnopharmacology, 97, 391-395. https://doi.org/10.1016/j.jep.2004.11.030

[8] Maghrani, M., Zegwash, N.A., Michel, J.B. and Eddouks, M. (2005) Antihypertensive Activity of Lepidium sativum L, in Spontaneously Hypertensive Rats. Journal of Ethnopharmacology, 100, 193-197. https://doi.org/10.1016/j.jep.2005.02.024 
[9] Mali, R.G., Mahajan, S.G. and Mehta, A.A. (2007) Lepidium sativum (Garden Cress): A Review of Contemporary Literature and Medicinal Properties. Oriental Pharmacy and Experimental Medicine, 7, 331-335. https://doi.org/10.3742/OPEM.2007.7.4.331

[10] Juma, A.B. (2007) The Effect of Lepidium sativum Seeds on Fracture Induced Healing in Rabbits. Medscape General Medicine, 9, 23-37.

[11] Dakhakhni, T.H., Raouf, G.A. and Ali A. (2020) Investigation of 2, 4-D Hepatotoxicity and Lipidium Sativum Antitoxicity on Rat Tissue Using FT-IR Spectroscopy. International Journal of Animal Biotechnology and Applications, 6, 17-29.

[12] Antoine, K.M., Mortazavi, S., Miller, A.D. and Miller, L.M. (2010) Chemical Differences Are Observed in Children's versus Adults' Latent Fingerprints as a Function of Time. Journal of Forensic Sciences, 55, 513-518.

[13] Fahey, J.W., Zalcmann, A.T. and Talalay, P. (2015) The Chemical Diversity and Distribution of Glucosinolates and Isothiocyanates among Plants. Phytochemistry, 56, 5-51. https://doi.org/10.1016/S0031-9422(00)00316-2

[14] Abdallah, H.M., Farag, M.A., Algandaby, M.M., Nasrullah, M.Z., Abdel-Naim, A.B., Eid, B.G., Safo, M.K., Koshak, A.E. and Malebar A.M. (2020) Osteoprotective Activity and Metabolite Fingerprint via UPLC/MS and GC/MS of Lepidium sativum in Ovariectomized Rats. Nutrients, 12, 2075-2095. https://doi.org/10.3390/nu12072075

[15] Kamani, M., Hosseini, E.S., Kashani, H.H., Atlasi, M.A. and Nikzad, H. (2017) Protective Effect of Lepidium sativum Seed Extract on Histopathology and Morphology of Epididymis in Diabetic rat Model. International Journal of Morphology, 35, 603-610. http://dx.doi.org/10.4067/S0717-9502201700020003

[16] Islam, F., Wang, J., Farooq, M.A., Khan, M.S.S., Xu, L., Zhu, J.W., Zhao, M., Muños, S., Li, Q.X. and Zhou, W.J. (2018) Potential Impact of the Herbicide 2, 4-Dichlorophenoxyacetic Acid on Human and Ecosystems. Environment International, 111, 332-351. https://doi.org/10.1016/j.envint.2017.10.020

[17] Thiel, N.A., Sachett, A., Schneider, S.E., Garbinato, C., Decui, L., Eichwald, T., et al. (2020) Exposure to the Herbicide 2,4-Dichlorophenoxyacetic Acid Impairs Mitochondrial Function, Oxidative Status, and Behavior in Adult Zebrafish. Environmental Science and Pollution Research, 27, 45874-45882.

https://doi.org/10.1007/s11356-020-10497-6

[18] Tichati, L., Trea, F. and Oual, K. (2020) Potential Role of Selenium against Hepatotoxicity Induced by 2,4-Dichlorophenoxyacetic Acid in Albino Wistar Rats. Biological Trace Element Research, 194, 228-236.

https://doi.org/10.1007/s12011-019-01773-9

[19] Evangelista de Duffard, A.M., Fabra de Peretti, A., Castro de Cantarini, S. and Duffard, R. (1993) Effects of 2, 4-Dichlorophenoxyacetic Acid Butyl Ester on Chick Liver. Archives of Environmental Contamination and Toxicology, 25, 204-211. https://doi.org/10.1007/BF00212131

[20] Troudi, A., Ben Amara, I., Samet, A.M. and Zeghal, N. (2012) Oxidative Stress Induced by 2,4-Phenoxyacetic Acid in Liver of Female Rats and Their Progeny: Biochemical and Histopathological Studies. Environmental Toxicology, 27, 137-145.

[21] Dakhakhni, T.H., Raouf, G.A. and Ali, A. (2016) Evaluation of the Toxic effect of the Herbicide 2,4-D on Rat Hepatocytes: an FT-IR Spectroscopic Study. European Biophysics Journal, 45, 311-320. https://doi.org/10.1007/s00249-015-1097-7

[22] Harada, Y., Tanaka, N., Ichikawa, M., Kamijo, Y., Sugiyama, E., Gonzalez, F.J. and Aoyama, T. (2016) PPARa-Dependent Cholesterol/Testosterone Disruption in Leydig Cells Mediates 2,4-Dichlorophenoxyacetic Acid-Induced Testicular Toxicity in 
Mice. Archives of Toxicology, 90, 3061-3071. https://doi.org/10.1007/s00204-016-1669-z

[23] Lerda, D. and Rizzi, R. (1991) Study of Reproductive Function in Persons Occupationally Exposed to 2,4-Dichlorophenoxyacetic Acid (2,4-D). Mutation Research Letters, 262, 47-50. https://doi.org/10.1016/0165-7992(91)90105-D

[24] Amel, N., Wafa, T., Samia, D., Yousra, D., Issam, C., Attia, N. and Mohamed, H. (2016) Extra Virgin Olive Oil Modulates Brain Docosahexaenoic Acid Level and Oxidative Damage Caused by 2,4-Dichlorophenoxyacetic Acid in Rats. Journal of Food Science and Technology, 53, 1454-1464.

https://doi.org/10.1007/s13197-015-2150-3

[25] United States Environmental Protection Association (2005) Reregistration Eligibility Decision for 2,4-D. United States Environmental Protection Association, New York.

[26] Willcox, J.K., Ash, S.L. and Catignani, G.L. (2004) Antioxidants and Prevention of Chronic Disease. Critical Reviews in Food Science and Nutrition, 44, 275-295. https://doi.org/10.1080/10408690490468489

[27] Akkas, S.B., Severcan, M., Yilmaz, O. and Severcan, F. (2007) Effects of Lipoic Acid Supplementation on Rat Brain Tissue: An FTIR Spectroscopic and Neural Network Study. Food Chemistry, 105, 1281-1288. https://doi.org/10.1016/j.foodchem.2007.03.015

[28] Robin, M., Sauvage, I., Grandperret, T., Descatoire, V., Pessayre, D. and Fromenty, B. (2005) Ethanol Increases Mitochondrial Cytochrom p450 in Mouse Liver and Rat Hepatocytes. FEBS Letters, 579, 6895-6902. 